\title{
The Views of Patients with Spinal Cord Injuries on their Rehabilitation Experience
}

\begin{abstract}
Background and Purpose: Spinal rehabilitation programs seek to enhance the residual functional abilities of people who have an acquired disabling impairment because of SCI. Very little has been published on how patients experience rehabilitation, and what the implication of their experience is on rehabilitation outcomes. The aim of this pilot study was to explore the views of patients with SCI regarding their experience of rehabilitation while in hospital.
\end{abstract}

Materials and Methods: A qualitative exploratory study using semi-structured interviews was employed. Twelve patients constituted the sample of convenience. Qualitative techniques were used to analyze the data.

Results: The study revealed a variety of psycho-emotional issues related to the patients' experience of rehabilitation. Positive issues included being treated humanly, being told the truth about their condition early on, family involvement in rehabilitation and being allowed to contribute to decision making regarding their rehabilitation. Negative issues were mainly their lack of insight into their health condition.

Conclusion: The study highlighted important psycho-emotional issues related to the patients' experience of rehabilitation. Rehabilitation personnel must consider these issues when working with patients with spinal cord injury, to ensure effective rehabilitation outcomes.

KEY WORDS: SPINAL CORD INJURIES; PATIENTS VIEWS; REHABILITATION EXPERIENCE.

\section{BACKGROUND AND PURPOSE}

Spinal cord injuries (SCI) remain one of the most serious and disabling injuries suffered by mankind today, often leading to permanent paralysis (Hart and Williams 1994). The number of people sustaining SCI has been rapidly increasing over the past few decades, with trauma being the most common cause of the injury. Violent trauma through gunshot is becoming the leading cause, followed by motor vehicle accidents (Hart and Williams 1994). Although there is no national database on the prevalence of SCI in South Africa, a report by the department of health estimates that 2000 patients are treated for SCI in public hospitals per annum nationally, representing one patient in every 20000

\section{CORRESPONDENCE TO:}

\section{DJ Mothabeng}

Physiotherapy Department

University of Pretoria

Tel: (012) 354-1200

Fax: (012) 354-1226

E-mail: joyce.mothabeng@up.ac.za members of the population (Department of Health, 2003).

Spinal rehabilitation programs seek to enhance the residual functional abilities of people who have an acquired disabling impairment because of SCI. The main goal of the rehabilitation programs is to facilitate adjustment to life by equipping the individual with skills and resources needed for community living (i.e. to empower them). The rehabilitation process therefore requires the full participation of the patient in all aspects. The patients experience of their rehabilitation is thus of crucial significance to the rehabilitation outcome.

This paper reports on a pilot study exploring the views of patients with spinal cord injury regarding their experiences of rehabilitation. According to Wade (2000), patients' perceptions are important personal factors that can impact on functioning or disability. It is important to evaluate patients' views regarding rehabilitation, "as it only them who appreciate the impact of their illness and the benefits of rehabilitation" (Edwards et. al. 2002)

\section{METHODOLOGY}

A cross sectional exploratory design using the phenomenological qualitative approach was employed for data collection. "Phenomenological studies examine human experience through the descriptions that are provided by the people involved" (Brink, 2000). The purpose of phenomenology is therefore to describe a certain aspect of life as it is lived by the participants (Domholdt 1993).

\section{Participants}

The study was conducted at three spinal units in Pretoria, which are clinical training sites for the Physiotherapy students from the University of Pretoria, The researchers asked the respective rehabilitation team members for the names of the patients who had undergone full rehabilitation and were about to be discharged from the spinal units. The patients were invited to participate in the study and those who consented constituted the sample of convenience. To qualify for inclusion in the study; the patients need to satisfy the following criteria: 
- Have sustained a first time spinal cord injury

- Be in the final stage of rehabilitation (i.e. have the full rehabilitation experience to be able to express opinion on the experience thereof)

\section{Procedure}

A literature informed semi-structured interview schedule compiled by the authors was used for data collection. It was pilot tested with two physiotherapists and two patients who scrutinized and commented on its content and user friendliness prior to implementation in the study.

Ethical clearance was obtained from the Ethics Committee of the Health Science Faculty at the University of Pretoria and the written permission was obtained from the superintendents of the participating hospitals to conduct the study. Written consent was also obtained from the participants, who received a detailed information leaflet (in English, Afrikaans, Sotho and Zulu) that was individually explained to them before they agreed to participate.

The interviews were conducted at the patients' convenient time and venue and lasted approximately one hour. The interviews were open-ended and assumed a conversational manner, while following a predetermined set of questions. The interviews were tape recorded and manually transcribed to create a verbatim transcript.

\section{Data analysis}

The transcripts were read thoroughly to identify emerging themes, which were then coded using open axial and selective coding. The codes of each interview were compared with those of other interviews to create broader categories that linked codes across categories. This process is called constant comparison. Each category was further divided into subcategories. Themes were identified and developed to substantiate each category.

The raw data were also sent to an independent coder who also performed open coding. Thereafter a meeting was held between the researchers and the independent coder for consensus discussion on the categories and themes reached independently.

Table 1: Demographic outline of the patients.

\begin{tabular}{|l|l|}
\hline Age & $\begin{array}{l}2 \text { Teens, both still at school } \\
10 \text { Age } 20 \text { to } 45\end{array}$ \\
\hline Gender & 1 Female and 11 males \\
\hline Marital states & $\begin{array}{l}4 \text { Were married with dependents } \\
5 \text { Single with no dependents. 3 single with dependence. }\end{array}$ \\
\hline Employment & $\begin{array}{l}\text { 9 Were permanently employed } \\
2 \text { Schoolchildren. 1 a housewife }\end{array}$ \\
\hline Dependents & $\begin{array}{l}\text { The eight with children have between 2 and 18 years } \\
\text { of age }\end{array}$ \\
\hline Cause of injury & $\begin{array}{l}2 \text { Were injured on duty } \\
2 \text { Were involved in motor vehicle accidents } \\
8 \text { Were injured by gunshots }\end{array}$ \\
\hline $\begin{array}{l}\text { Length of stay } \\
\text { in hospital }\end{array}$ & \begin{tabular}{l} 
Ranges between 3 months and 9 months \\
\hline $\begin{array}{l}\text { Duration of } \\
\text { physiotherapy }\end{array}$
\end{tabular} \\
\hline
\end{tabular}

\section{DISCUSSION OF THE RESULTS Demographics}

Twelve patients participated in the study. They were 11 males and one female, with their ages ranged from 19 to 45 years. They had been in hospital for an average of three months and were all fully rehabilitated in relation to the level of their lesion by the time they participated in the study (i.e. Physical rehabilitation was complete and all issues of reintegration e.g. work, family, compensation and disability grant as applicable had been addressed) The demographic profile of the participants is shown in table 1.

\section{Patients' views on rehabilitation}

The study was intended to establish, from the patients' point of view, how they experienced rehabilitation following SCI. Three categories of themes related to the patients' experiences namely emotions, dependence and insight were identified. These themes are discussed henceforth in relation to patient's responses to some of the interview questions.

\section{Emotions}

This theme included emotions that patients experience about themselves, their families, their spouses and their friends. When asked the question "How do you cope with your condition" the following emotions were elicited from the patients:

\section{- Acceptance}

".. You can either sit and cry, or do something with your life...”

"I am not happy obviously, but there is nothing I can do..."

In the first statement the emotion of acceptance is stated positively, suggesting that the patient is determined to move on with life. The second patient sounds like he has accepted his 'fate', but in a negative sense of giving in. This type of acceptance is not motivating to the patient and may affect his rehabilitation negatively. Acceptance is one of the coping skills that a patient needs to develop to be able to cope with the injury (Elfstrom et al. 2002). According to Brillhart and Johnson (1997) acceptance is a journey for the patients to realize that they are lucky that the injuries were not more severe and that they are still who they were before.

- Sense of loss

"Before the injury, I had plans to marry...all is lost... hopeless"

The sense of loss expressed above suggests that he has nothing to look forward to in life. This will discourage him from working hard in rehabilitation as he has lost hope. Nielsen (2003) reported that persons that were involved in traumatic events and suffered a spinal cord injury respond in fear, hopelessness or horror. Hopelessness is a distressing feeling that can lead to further depression, affecting the rehabilitation out- 
come of the SCI patient negatively (Elfstrom, Kreuter, Ryden, Persson, and Sullivan 2002.

\section{- Family support}

"My wife is helping a lot. She visits me often, and that helps".

Most of the patients experienced positive emotions of support surrounding their family and friends that helped them on the journey, although a couple of them had some doubt about their family and friends. Accordingly, Brillhart and Johnson (1997) found that socialization with family and friend helped patients to cope. On the other hand, Elfstrom et al. (2002) reported that family support was associated with elevated psychological distress due to external control over the patient which may contribute to higher level of depression among patients. This was not found to be the case in this study except in the patient who felt her house chores were her pride and joy, and wanted to get better so she could perform them again.

The question "How do you feel about your condition now" evoked an array of negative emotion towards others including:

\section{- Anger}

"The government is doing nothing about the crime"

- Doubt

"My wife is very young. I cannot expect her to stay with me..."

\section{- Worry/guilt}

"..My man never did anything for me. I did all the housework. I must get better.." - Loneliness

"I have no real family in South Africa. My friends come, but I don't know if they will always be there"

\section{- Frustration}

"I can't take myself to the bathroom. This is very frustrating...embarrassing."

These emotions although negative, can have a potentially positive influence on rehabilitation outcome, if patients choose to work through them. For this to happen, the patients need to have a goal to work towards. Most of the patient expressed a desire to get better and to go home. One patient said "for the sake of my children".

\section{Dependence}

When asked "What goals did you want to achieve..?" all patients but one felt it was not up to them to set goals for rehabilitation. They gave responses like

"They teach me everything I need to know"

"They know what I need. What can I say? I just do what they tell me"

The only patient who felt he needed to have a say expressed the following sentiments:

"We must be allowed to choose which physiotherapist treats us. You watch patients getting good treatment and you cannot change physios."

The responses of the patients suggest that they are dependent on their therapist for all aspects of the rehabilitation, including setting goals. They did not contribute to decision making (goal setting) regarding their rehabilitation, and need to be empowered.

The relationship between therapist and the patient is an important factor in goal setting (Livingstone 1985). Payton and Nelson (1996) reported variations in patients perceptions regarding participation in goal setting, suggesting some degree of dependence.This dependence causes one to question the therapists' approach to rehabilitation. It suggests that therapists are still using the old 'medical' model of telling patients what to do instead of jointly set goal for them with them (op cit).

When asked if they were satisfied with their experience of rehabilitation, all the patients agreed, except for one teenager (who was also a prisoner). His reasons were:

"Nurses wake us too early - it is not fair..."

"Therapists are racists, they do not treat us the same"

The one patient who was reportedly not satisfied was probably bitter because of psychosocial circumstances. Psychosocial issues do influence one's attitude towards rehabilitation (Wade 2000) as it is therefore no wonder this patient was unhappy. He was a teenage father of a one year old, still at school and arrested for armed robbery. The end of rehabilitation meant going to jail for him and he was generally angry with life.

Patient satisfaction is an important outcome measure of rehabilitation (Kramer 1997). Although satisfaction was not objectively measured with a validated tool in this pilot study, it is noteworthy that majority of the patients in this study reported satisfaction with heir rehabilitation experience. It would be interesting to find out what the satisfaction rating would be if an objective validated measure is used. The dependence of patients in this study however suggests that these patients may be more appreciative than satisfied with the rehabilitation they experienced.

\section{Insight}

To determine if they had insight into their health condition, patients were asked the question "Do you know what caused you to be in this condition?" Half the patients had a good insight about the cause of their injuries, like the patient who answered:

"I was shot through the spine and my spinal cord got injured. Now I am paralysed because..."

One patient said that it helped that the doctor explained to him early on that he wouldn't be able to walk again. Most of the patients also had good knowledge about complications of SCI and how to prevent them. This is important, because according to Brillhart et al (1997) patients find comfort in being educated so they can be able to educate their family members.

Some patients however, seemed to have poor insight, as can be deduced from the following responses:

"I don't know, I am not a doctor. They told me something about the spinal cord...I don't know" (Poor insight and anger)

"I don't know anything. I don't know what happened" (Ignorance/denial)

The observed lack of knowledge/ ignorance is a concern as the patients in this study were fully rehabilitated and going home to look after themselves.

Cooper (1998) stated that patients' beliefs or perceptions about their health condition mediate outcome variables. It is important to explore what causes or reasons patients attribute to their health condition as these affect the patients response to intervention. Previous studies with different patient groups have shown that patients who have insight into their health problems tend to take responsibility for their own health and to 
have a better quality of life outcome despite the severity of their illness or disability (Pound et al 1995, Eales and Stewart 2002). The aspect of self responsibility and its impact on outcomes has however not been studied among the SCI population in South Africa and globally.

\section{CONCLUSION}

This study highlighted emotions, dependence and insight as important themes of psycho-emotional issues related to the patients' experience of rehabilitation. Positive issues included being told the truth about their condition early on in the rehabilitation, family involvement in rehabilitation and being allowed to contribute to decision making regarding their rehabilitation. Negative issues included the patients' lack of insight into their health condition. Rehabilitation personnel must endeavor to minimize the negative and maximize issues when working with patients with spinal cord injury, as these may have an important role in the outcome of rehabilitation. Other variables like socioeconomic factors which were not explored in this study need to be considered also.

\section{LIMITTIONS AND RECOMMENDATIONS}

A major limitation of this study was the cross sectional design used. The data collection was limited to a specified period and only patients who were being discharged in that period qualified for participation. As a result, perceptions could not be probed to saturation of data and member checking could also not be done for data trustworthiness as the patients were discharged.

The small sample size, although not a problem in qualitative research, limited the amount of rich data that could have been obtained for exploration. It is therefore recommended that future studies should be longitudinal at intervals to include a comparison of change in perception (e.g. over one year) and that larger samples be used.

\section{ACKNOWLEDGEMENT}

The authors would like to thank the management, therapists and patients from the three hospitals who made this study possible. This paper was presented at the second International congress of the South African Society of Physiotherapy in 2005.

\section{REFERENCES}

Brillhart B, Johnson M (1997) Motivation and coping process of adults with disabilities: A qualitative study. Rehabilitation Nursing 22(5):249-255

Brink HI 2002 Fundamentals of Research Methodology for Health Care Professionals. Juta \& Co, Cape Town

Chase WB, Cornille TA, English RW (2000) Life Satisfaction Among Persons with Spinal Cord Injuries. Journal of Rehabilitation 66: $14-20$

Cooper AC (1998) Whose Illness is it anyway? Why patient Perceptions Matter. International Journal or Clinical Practice 52(8):551-555

Department of Health (accessed 24/04/2003) Spinal Cord Injury Rehabilitation. Available at www.caa.gov.za/doh/mts/reports/spinal.html

De Vos AS (ed), Strydom H, Fouche CB, Delport CSL (2002) Research at grass roots, 2nd edn Van Schaik Publishers, Pretoria

Dijkers M (1997) Quality of life after spinal cord injury: a meta analysis of the effects of the disablement process. Spinal cord $35: 829-840$

Domholdt E 1993 Physical Therapy Research: Principles and Applications. WB Saunders Company, USA

Eales CJ Noakes TD Stewart AV Becker P (2004) Self responsibility predicts the successful outcome of coronary artery bypass surgery. South African Journal of Physiotherapy 60 (2) 11-19

Elfstrom ML, Kreuter M, Ryden A, Persson LO, Sullivan M, (2002) Effect of coping on psychological outcome when controlling for background variables: a study of traumatically spinal cord lesion persons. Spinal Cord 40 (8): 408-415

Galvin L.R (2001) The impact of coping on emotional adjustment to spinal cord injury: Review of the literature and application of a stress appraisal and coping formulation. Paraplegia, 39, 615-627.

Hicken BL, Putzke D.J, Novack T, Shever M and Richards SS (2002). Life satisfaction following spinal cord injury and traumatic brain injury. Journal of Rehabilitation Research and Development 39(3):359-366
Keith RA (1997) Response and commentary on: Rehabilitation care and outcomes from the patient's perspective. Medical care 35: JS61 - JS63

Kramer MA (1997) Rehabilitation care and outcomes from the patient's perspective. Medical care 35:JS48 - JS57

Neilsen MS (2003) Post-traumatic stress disorder and emotional distress in persons with spinal cord lesions. Spinal cord 41(3): 296-302

Payton OD, Nelson CE (1996) Apreliminary study of patients' perceptions of certain aspects of their physical therapy experience. Physiotherapy Theory and Practice 12: 27 - 38.

Pound P, Bury M, Compertz P, Ebrahim S (1995) Stroke patients' views on their admission to hospital. British journal of Medicine 311: $18-22$

Putzke, J.D., Richards, S., Hicken, B.L., DeVivi, MJ (2002). Predictors of Life Satisfaction: A spinal cord injury cohort study. Archives of Physical Medicine Rehabilitation, 83, 555-561.

Putzke JD, Richards JS, Michael J (2001) Gunshot Versus Non-gunshot Spinal Cord Injury: Acute Care and Rehabilitation Outcomes. American Journal of Physical Medicine and Rehabilitation 80(5): 366-370

Wade DT (2000) Editorial - Personal context as a focus for rehabilitation. Clinical rehabilitation14: 115 - 118

Tooth LR, Ottenbacher KJ, Smith PM, Illig SB, Linn RT, Granger CV (2004) Satisfaction with Medical Rehabilitation after Spinal Cord Injury. Health Services Research 29(2): 211-218 